\title{
HYPOSPADIAS REPAIRIN CHILDREN: 10-YEARS EXPERIENCE AT SHAIKH ZAYED HOSPITAL LAHORE.
}

\footnotetext{
1. MBBS, FCPS (Paediatric Surgery) Associate Professor Department of Paediatric Surgery Shaikh Zayed Hospital Lahore.

2. MBBS, FRCS

Professor \& Head

Department of Paediatric Surgery Shaikh Zayed Hospital Lahore.

3. MD, MS (Paediatric Surgery)

Senior Registrar

Department of Paediatric Surgery

Shaikh Zayed Hospital Lahore.
}

Correspondence Address:

Dr. Muhammad Ali Sheikh

Flat no 8 Block A, Doctors Flats,

Shaikh Zayed Hospital Lahore.

drali444@yahoo.com

Article received on:

27/11/2018

Accepted for publication:

$16 / 04 / 2019$

Received after proof reading:

$25 / 06 / 2019$

\section{Muhammad Ali Sheikh', Tariq Latif², Jamil Akhter Munir Ahmad ${ }^{3}$}

ABSTRACT... Hypospadias is one of the common urogenital condition affecting male children. Multiple factors have been reported by different studies that contribute towards hypospadias, including in utero growth retardation, higher maternal age and endocrine disruptors. Usually multiple surgical procedures are required for correction of hypospadias especially in cases of proximal hypospadias associated with chordee. The purpose of study was to report the early outcomes after single stage repair for distal hypospadias and staged repair for proximal hypospadias over the last 10 years in our department. Study Design: Descriptive Study. Setting: Department of Paediatric Surgery, Shaikh Zayed Hospital Lahore. Period: January 2006 to December 2016. Materials \& Methods: This study was conducted in Department of Pediatric Surgery, Shaikh Zayed Hospital Lahore. All the patients who were operated between January 2006 to December 2016 for hypospadias or their complications in our unit were included. Data was collected from chart review and outpatient follow up. Data for age at presentation, type of anomaly, congenital curvature, testosterone stimulation, surgical procedure and complications with their management were collected. Patients were divided in two groups depending upon whether single stage procedure was performed or two stage surgery was undertaken. All patients with glandular hypospadias had meatal advancement but glanuloplasty was done in selected cases. Patients with distal hypospadias without chordee underwent tubularized incised plate urethroplasty (TIP) repair. Patients with proximal hypospadias had two stage surgery with correction of chordee with grafting and tubularization of graft after 6 months. Data was analyzed by SPSS $v 22$. Results: During the study period 134 patients with hypospadias or its complication were managed. Out of these 90 patients met our inclusion criteria. The mean age of patients was 5.0 years. Sixty three $(70 \%)$ had distal hypospadias. MAGPAI was performed in 12 (13.3\%), TIP repair in 51 (56.7\%), Bracka I in 25 (27.8\%), Bracka II in 18 (20.0\%) and Mathieu repair in 2 (2.2\%) patients. Both the patients with Mathieu repair had dehiscence. The most common complication in distal cases was meatal stenosis. In patients with distal hypospadias $10.8 \%$ developed fistula while $44.5 \%$ of patients with proximal hypospadias developed fistula. Conclusion: Repair of proximal hypospadias with chordee is associated with more complications. Outcomes may be improved by specialized training with adequate workload.

Key words: $\quad$ Chordee, Children, Hypospadias, MAGPAI, TIP, Urethroplasty.

Article Citation: Sheikh MA, Latif T, Ahmad JAM. Hypospadias repair in children: 10-years experience at Shaikh Zayed Hospital Lahore. Professional Med J 2019; 26(7):1020-1026. DOI: 10.29309/TPMJ/2019.26.07.1622

\section{INTRODUCTION}

Hypospadias is one of the common urogenital condition affecting male children. It is second most common urogenital condition after undescended testis and is characterized by abnormal location of urethral meatus on ventral surface of penis due to incomplete closure of penile structures during fetal life. ${ }^{1}$ It is associated with mal development of corpus spongiosum, ventral prepuce and ventral penile curvature in some of cases. ${ }^{2}$ Incidence of hypospadias varies according to region and reported to be between 1 in 125 live births to 1 in 300 live male births. In Europe the overall incidence is 18.61 per 10000 live births. $^{3}$

Hypospadias is often classified as distal and proximal varieties according to preoperative location of meatus. Most of the cases of hypospadias are distal (around 70\%) in variety and have good prognosis, whereas proximal 
cases are more complex and usually associated with ventral curvature. ${ }^{4}$ Proximal hypospadias may be associated with cryptorchidism, enlarged utricle and underdeveloped penis confusing with intersex disorders. ${ }^{2}$

The exact etiology of hypospadias is still unknown. Multiple factors have been reported by different studies that contribute towards hypospadias, including in utero growth retardation, higher maternal age and endocrine disruptors.,5 The human males who are exposed to diethylstilbestrol in utero are at risk for developing a broad range of reproductive tract problems, including hypospadias. ${ }^{4,5}$

Present study was designed keeping in mind that results of surgery for proximal hypospadias are different from distal hypospadias, secondly different procedures are used for correction of these anomalies. The purpose of study was to report the early outcomes after single stage repair for distal hypospadias and staged repair for proximal hypospadias with chordee over the last 10 years in our department.

\section{PATIENTS \& METHODS}

This study was conducted in Department of Pediatric Surgery, Shaikh Zayed Hospital Lahore. All the patients who were operated between January 2006 to December 2016 for hypospadias or their complications were included. Patients who were not operated primarily in our unit, were excluded.

Data was collected retrospectively from chart review and outpatient follow up. Data for age at presentation, type of anomaly, congenital curvature, testosterone stimulation, surgical procedure, stent and dressing used and complications with their management were collected. Hypospadias was classified according to location of meatus into glanular, coronal/ subcoronal, distal penile, mid penile, proximal penile, peno-scrotal, scrotal and perineal.

All patients with glanular hypospadias had meatal advancement but glanuoplasty was done in selected cases. Patients with coronal, subcoronal, distal penile and mid penile without chordee underwent tubularized incised plate urethroplasty (TIP) repair as described by Snodgrass. For TIP repair appropriate size feeding tube was used as stent and kept for 7 days. All patients had midline slit in urethra and urethra was closed with $5 / 0$ or $6 / 0$ polydioxanone (PDS). Dartos pedicle flap was dissected from the prepeutial hood and dorsal skin. It was either rotated from side or buttonholed and transposed ventrally to cover the entire neourethra. Dorsal hood subcutaneous tissue was used as second layer on urethral tube in cases where prepeuce was available and in case of non-availability of prepuce local tissue was used. Skin was closed with 5/0 (polyglactin) and wound was dressed. Dressing was changed after 48 hours under sedation. Stent was removed on $7^{\text {th }}$ postoperative day and patients were discharged after they had passed urine. Patients were seen in outpatient clinic at 2 weeks, 3 months and 6 months for assessment of outcome and to note any complications. Any complication other than meatal stenosis was repaired 6 months after the primary surgery.

Patients with proximal hypospadias with chordee were repaired by two stage technique described by Bracka. In first stage correction of chordee with grafting was done. Graft was harvested from prepeuce and in case of non-availability of prepeuce, retroauricular skin was used. The second stage was performed at least 6-12 months after the first stage, so that the graft had matured and unlikely to undergo any further contraction. At stage 2, tubularization of the plate was done over a catheter. The graft which was used for creation of neourethra was adjusted according to the size of the penis and size of the catheter, so as to form a tube of uniform circumference without any tension on the suture line. The second layer was raised from the Dartos fascia and was used to cover the neourethra. Skin closure formed the third layer. Both the first and the second layers were sutured with interrupted $6 / 0$ or $5 / 0$ polydioxanone (PDS). The catheter was removed on the seventh postoperative day, after which the micturition and urinary stream were assessed. The patients were followed up at 2 weeks, 3 months and 6 months for assessment of outcome 
of surgery. Surgery for any complication, such as fistula repair, was usually attempted at least 6 months after the stage 2 .

\section{RESULTS}

During the study period 134 patients with hypospadias or its complication were managed. Out of these 90 patients met our inclusion criteria.

The mean age of patients was 5.0 years with minimum of 7 months and maximum of 14 years. Most of the patients (68.9\%) were between 1-5 years of age. The details of patients with different types of hypospadias is shown in Table-I.

All the patients with penoscrotal (18), scrotal (3), two (2) cases of mid penile and two patients of proximal penile (2) hypospadias had associated ventral chordee which required correction. One patient of mid penile and one of proximal penile had minimal chordee and were repaired by tubularized incised plate urethroplasty (TIP) technique and both of them developed urethral fistula.

Testosterone stimulation was required in 16 $(17.8 \%)$ of patients. None of the patients with distal hypospadias (glanular, coronal, sub-coronal, distal penile) had testosterone stimulation. One patient each of mid penile and proximal penile, 13 patients of penoscrotal hypospadias and 1 patient of scrotal hypospadias had testosterone stimulation. Single injection of testosterone was used in 2 (2.2\%), two injections in 5 (5.6\%) and three injections in 9 (10.0\%) patients.

No stent was used in 12 (13.3\%) patients who had meatal advancement and were discharged next day. Appropriate sized nasogastric tube was used as stent in cases of TIP repair and foley's catheter was used after chordee correction and grafting. Different types of procedures performed are shown in Table-II.

\begin{tabular}{|l|c|c|}
\hline Glanular & 6 & $6.7 \%$ \\
\hline Coronal/subcronal & 32 & $35.6 \%$ \\
\hline Distal penile & 25 & $27.8 \%$ \\
\hline Mid penile & 3 & $3.3 \%$ \\
\hline Proximal penile & 3 & $3.3 \%$ \\
\hline Penoscrotal & 18 & $20.0 \%$ \\
\hline Scrotal & 3 & $3.3 \%$ \\
\hline & \multicolumn{2}{|c|}{ Table-l. Type of anomaly } \\
\hline
\end{tabular}

\begin{tabular}{|l|c|c|}
\hline \multicolumn{1}{|c|}{ Procedure } & N=108 & Percentage \\
\hline MAGPAI & 12 & $13.3 \%$ \\
\hline Snodgrass & 51 & $56.7 \%$ \\
\hline Mathieu repair & 2 & $2.2 \%$ \\
\hline Chordee correction \& Grafting (I) & 25 & $27.8 \%$ \\
\hline Tubularization of graft (II) & 18 & $20.0 \%$ \\
\hline \multicolumn{2}{|c|}{ Table-II. Different procedures performed }
\end{tabular}

Patients were divided in to single stage surgery group (Group A) and staged repair group (Group B) to note complications. There were 65 (72.2\%) patients in group $A$ and all of them had distal hypospadias (glanular, coronal, subcoronal, distal penile) without chordee. Staged repair was undertaken in 25 (27.8\%) patients and all of them had proximal hypospadias with chordee. These patients had chordee correction and grafting as first stage and 18 of them underwent stage two i.e tubularization of graft, while 7 are waiting for urethroplasty.

The patients $(n=65)$ who had single stage procedure, 23 (35.4\%) of them had complications as shown in Table-III.

\begin{tabular}{|c|c|c|c|c|c|c|c|c|}
\hline & \multicolumn{2}{|c|}{ MAGPAI } & \multicolumn{2}{|c|}{ Snodgrass } & \multicolumn{2}{|c|}{ Mathieu repair } & \multicolumn{2}{|c|}{ Total } \\
\hline No Complication & 12 & $100.0 \%$ & 30 & $58.8 \%$ & 0 & $0.0 \%$ & 42 & $64.6 \%$ \\
\hline Extravasation of Urine & 0 & $0.0 \%$ & 3 & $3.9 \%$ & 0 & $0.0 \%$ & 3 & $3.1 \%$ \\
\hline Fistula & 0 & $0.0 \%$ & 4 & $7.8 \%$ & 0 & $0.0 \%$ & 4 & $6.2 \%$ \\
\hline Partial Dehiscence & 0 & $0.0 \%$ & 1 & $2.0 \%$ & 2 & $100.0 \%$ & 3 & $4.6 \%$ \\
\hline
\end{tabular}


The mean age in group A patients was 5.2 years and $86.2 \%$ of patients were less than 8 years of age. There was no statistically significant difference in mean age between the two groups.

Meatal advancement was done in 12 cases and none of them had complication. Snodgrass repair was done in 51 cases and $30(58.8 \%)$ patients had no complication. Meatal stenosis was noted in $14(27.5 \%)$, fistula in $4(7.8 \%)$, extravasation of urine in $3(5.8 \%)$ and partial dehiscence of repair in $1(2 \%)$ patient. Mathieu repair was done in only 2 cases and both of them had partial dehiscence of repair.

The most common complication was meatal stenosis seen in $16(24.6 \%)$ patients. Thirteen $(81.2 \%)$ of these patients responded to meatal dilatation and $3(18.8 \%)$ required meatotomy under general anesthesia.

Partial dehiscence of repair (4.6\%) was recorded separately from urethral fistula $(6.2 \%)$. If both taken together then urethrocutaneous fistula developed in $10.8 \%$ of patients in group A. Three of our patients after TIP repair had extravasation of urine after removal of stent on $7^{\text {th }}$ day. Two of these patients required suprapubic cystostomy and one was managed by re-insertion of foleys catheter. Different procedures undertaken to manage complications in group $A$ are shown in Table-IV.

The mean age in group B was 4.4 years. In group $B$ patients after correction of chordee graft was placed as stage $\mathrm{I}$. Out of 25 patients who had chordee correction and placement of graft, one patient had loss of graft and redo grafting was done. Eighteen patients underwent Bracka II and $55.6 \%$ had complications and details are in Table-V. The most common complication was urethrocutaneous fistula (44.5\%) combining partial dehiscence and fistula formation. Meatal stenosis was noted in $11.1 \%$ of cases in group B.

\begin{tabular}{|l|c|c|c|c|c|c|c|c|c|}
\hline & \multicolumn{2}{|c}{ MAGPAI } & \multicolumn{2}{c}{ Snodgrass } & \multicolumn{3}{c|}{ Mathieu repair } & \multicolumn{2}{c|}{ Total } \\
\hline & $\mathrm{N}=12$ & $\%$ & $\mathrm{~N}=51$ & $\%$ & $\mathrm{~N}=2$ & $\%$ & $\mathrm{~N}=65$ & $\%$ \\
\hline Redo surgery & 0 & $0.0 \%$ & 1 & $2.0 \%$ & 2 & $100 \%$ & 3 & $4.6 \%$ \\
\hline Fistula repair & 0 & $0.0 \%$ & 4 & $7.8 \%$ & 0 & $0.0 \%$ & 4 & $6.1 \%$ \\
\hline Meatal dilatation & 0 & $0.0 \%$ & 13 & $25.5 \%$ & 0 & $0.0 \%$ & 13 & $20.0 \%$ \\
\hline Meatotomy & 0 & $0.0 \%$ & 3 & $5.9 \%$ & 0 & $0.0 \%$ & 3 & $4.6 \%$ \\
\hline Suprapubic Cystostomy & 0 & $0.0 \%$ & 2 & $4.0 \%$ & 0 & $0.0 \%$ & 2 & $3.0 \%$ \\
\hline
\end{tabular}

Table-IV. Procedures to manage complications in Group A

\begin{tabular}{|c|c|c|c|c|c|c|c|c|c|c|c|}
\hline & & \multicolumn{10}{|c|}{ Type of anomaly } \\
\hline & & \multicolumn{2}{|c|}{ Mid penile } & \multicolumn{2}{|c|}{ Proximal penile } & \multicolumn{2}{|c|}{ Penoscrotal } & \multicolumn{2}{|c|}{ Scrotal } & \multicolumn{2}{|c|}{ Total } \\
\hline & & $\mathrm{N}=2$ & $\%$ & $\mathbf{N}=2$ & $\%$ & $\mathrm{~N}=18$ & $\%$ & $\mathrm{~N}=3$ & $\%$ & $\mathrm{~N}=\mathbf{2 5}$ & $\%$ \\
\hline Primary Procedure & Bracka1 & 2 & $100.0 \%$ & 2 & $100.0 \%$ & 18 & $100.0 \%$ & 3 & $100.0 \%$ & 25 & $100.0 \%$ \\
\hline \multirow{2}{*}{$\begin{array}{l}\text { Complication after } \\
\text { primary procedure }\end{array}$} & No & 2 & $100.0 \%$ & 2 & $100.0 \%$ & 17 & $94.4 \%$ & 3 & $100.0 \%$ & 24 & $96.0 \%$ \\
\hline & Loss of graft & 0 & $0.0 \%$ & 0 & $0.0 \%$ & 1 & $5.6 \%$ & 0 & $0.0 \%$ & 1 & $4.0 \%$ \\
\hline \multirow[b]{2}{*}{$\begin{array}{l}\text { Stage } 2 \text { Procedure } \\
\text { performed }\end{array}$} & Completed & 1 & $50.0 \%$ & 2 & $100.0 \%$ & 13 & $72.2 \%$ & 2 & $66.7 \%$ & 18 & $72.0 \%$ \\
\hline & $\begin{array}{l}\text { Waiting for } \\
\text { Bracka } 2\end{array}$ & 1 & $50.0 \%$ & 0 & $0.0 \%$ & 5 & $27.8 \%$ & 1 & $33.3 \%$ & 7 & $28.0 \%$ \\
\hline \multirow{4}{*}{$\begin{array}{l}\text { Complications after } \\
\text { stage } 2\end{array}$} & No & 0 & $0.0 \%$ & 1 & $50.0 \%$ & 6 & $46.2 \%$ & 1 & $50.0 \%$ & 8 & $44.4 \%$ \\
\hline & Fistula & 1 & $100.0 \%$ & 0 & $0.0 \%$ & 1 & $7.7 \%$ & 1 & $50.0 \%$ & 3 & $16.7 \%$ \\
\hline & $\begin{array}{l}\text { Meatal } \\
\text { stenosis }\end{array}$ & 0 & $0.0 \%$ & 0 & $0.0 \%$ & 2 & $15.4 \%$ & 0 & $0.0 \%$ & 2 & $11.1 \%$ \\
\hline & $\begin{array}{l}\text { Partial } \\
\text { dehiscence }\end{array}$ & 0 & $0.0 \%$ & 1 & $50.0 \%$ & 4 & $30.8 \%$ & 0 & $0.0 \%$ & 5 & $27.8 \%$ \\
\hline
\end{tabular}




\section{DISCUSSION}

Hypospadias is a condition for which many procedures have been described. Different techniques have been described and still search is going on to find a procedure which could provide better results than currently practiced procedures. A boy born with hypospadias is a cause of great concern for the family especially in our part of the world. Although most of distal hypospadias without chordee can be corrected in single stage, most of proximal hypospadias associated with chordee require multiple procedures. Among many procedures described, the most widely practiced procedure for distal hypospadias is TIP (Tubularized incised plate urethroplasty) repair described by Snodgrass. This technique is easy to teach and learn with good cosmetic appearance and reproducible results. For proximal hypospadias with chordee staged repair described by Bracka has gained wide acceptance.

As variety of techniques and their modifications are available, we restricted our self to mainly three techniques. Meatal advancement in cases of glanular and coronal hypospadias, TIP repair for distal cases with no chordee and two stage technique for proximal cases. In our institute we perform TIP repair in patients with distal hypospadias while in proximal hypospadias we perform two stage procedure with correction of chordee and grafting as first stage and urethroplasty as second stage.

The desired outcome in the surgery of hypospadias is straight penis in erection allowing sexual intercourse, ability to pass urine in standing position with normal stream and direction with meatal opening near tip of glans. ${ }^{6}$

The mean age in our patients was 5.0 years and $65.6 \%$ were between $2-5$ years of age. Bello A et al from Nigeria reported their 10 years experience and the mean age in their patients was 1.97 years. $^{7}$ The mean age reported by Shadrach et al in their study was 2.6 years. ${ }^{2}$ A follow up study from Canada reported 1.96 years mean age in their patients. ${ }^{8}$ A meta-analysis comparing hypospadias surgery outcomes noted that in
North America hypospadias patients underwent first procedure during first two years, European patients during first three years and Chinese patients during first five years. ${ }^{9}$ although this study noted that complications were minimal if hypospadias was repaired in younger patients but Snodgrass reported that age at surgery was not an independent risk factor for urethroplasty complications. ${ }^{10}$ Previously we used to delay the patient if glans size was not adequate in distal cases because of risk of glans dehiscence, but with recent evidence showing that pre-incision glans width do not correlate with complications, we have changed our practice and started doing surgery in early age group. ${ }^{11}$ Similarly we do not stimulate patients of distal hypospadias with testosterone to increase the size of glans or penis as it does not affect outcome. ${ }^{10}$ In our study testosterone stimulation was used only in penoscrotal and scrotal cases with severe chordee to have adequate size penis before surgery.

Most of our patients $63(70.1 \%)$ were of anterior variety and similar results had been reported by other authors. ${ }^{7,8,9}$ Ventral curvature (chordee) was noted in 25 (27.8\%) patients which required correction and all of them had two stage procedure. Shadrach et al reported chordee in $20.8 \%$ of their patients. Bello et al had severe chordee in $26 \%$ of their patinets. ${ }^{7}$ For chordee correction, penis was completely degloved and any tethering skin was excised. The urethral plate was excised and bed prepared for grafting.

In single stage surgery group (Group A) 23 (35.4\%) patients had complications. The patients who had glanular or coronal hypospadias were operated only if they had downward directed stream. In this group 10 patients had only meatal advancement only 2 had meatal advancement and glanuloplasty. None of the patients in this subset had any problems. We believe that only those cases of distal hypospadias should be corrected who had functional problem, otherwise merely correcting a cosmetic problem might end up with a patient having both cosmetic and functional problem. ${ }^{12}$ The most common complication (24.6\%) in group A was meatal stenosis and all of these patients had TIP repair. This could have 
been due to closure of glans too far distally. So we changed our practice and now incidence of this complication has decreased. Most of the cases (13 out of $16,81.2 \%$ ) responded to meatal dilatation alone while 3 patients required meatotomy. Meatal stenosis can be avoided by incising the urethral plate deeper in cases of flat urethral plate, tubularization of urethra till midglans level and closure of the glans wings over the neo urethra rather than suturing to it. ${ }^{10}$

Following TIP repair on removal of stent on $7^{\text {th }}$ day three of our patients developed urinary retention followed by extravasation of urine in subcutaneous planes of penis resulting in marked edema and failure to micturate. Two of these patients required emergency suprapubic cystostomy and in one patient we were able to pass catheter per urethra. These patents required urinary diversion of another 2 weeks and then settled. We think this could be due to abnormal spasms of detrusor due to the stent and we now routinely use anticholinergic drugs to suppress bladder spasms in all cases of hypospadias and since then no patient had this problem.

Urethocutaneous fistula developed in 4 (6.2\%) and partial dehiscence in $3(4.6 \%)$ patients in group A. Mathieu repair was done in two cases and both of them had partial dehiscence, so this procedure was not done in subsequent patients. The reported urethral fistula rate after TIP repair varies between $4-8.2 \%$ for primary distal repairs. ${ }^{13}$ Our result of distal hypospadias repair using TIP repair are comparable to these studies. Partial dehiscence was noted in 1 case of TIP repair involving glans and required second procedure for correction.

In staged procedure group (Group B) one patient lost skin graft after correction of chordee and grafting due to infection. He underwent grafting again and graft was harvested from retroauricular skin. After urethroplasty $56.6 \%$ had complications with partial dehiscence of repair in $27.8 \%$ and urethrocutaneous fistula in $16.7 \%$ and meatal stenosis in $11.1 \%$ of patients. The reported complication rate after repair of proximal hypospadias is $40-60 \%$, with urethrocutaneous fistula being the most common followed by meatal stenosis. ${ }^{2,7,13}$ The high rate of complication in proximal cases may be due to long suture line and non-availability of tissue for water proofing layer.

\section{CONCLUSION}

The most common complication in our study was urethral fistula in proximal cases and meatal stenosis in distal variety. Proximal hypospadias had more complications and required multiple surgical procedures for correction. Outcome may be improved by specialized training with adequate workload and use of intraoperative magnification. TIP repair is a good choice for distal hypospadias and two stage Bracka technique for proximal hypospadias with chordee.

\section{Copyright $@ 16$ Apr, 2019.}

\section{REFERENCES}

1. Horst HJR, Wall LLD. Hypospadias, all there is to know. Eur J Pediatr 2017; 176:435-41.

2. Shadrach OIA, Atim T, Eniola BS, Ohemu AA. Hypospadias repair and outcome in Abuja, Nigeria: A 5-year single centre experience. Afr J Paediatr Surg 2015; 12:41-44.

3. Bergman JE, Loane M, Vrijheid M, Pierini A, Nijman RJM, Addor MC, et al. Epidemiology of hypospadias in Europe: a registry-based study. World J Urol. 2015; 33:2159-67.

4. Baskin LS, Ebbers MB. Hypospadias: Anatomy, etiology and technique. J Pediatr Surg. 2006; 41:46372.

5. Brouwers MM1, Feitz WF, Roelofs LA, Kiemeney LA, de Gier RP, Roeleveld N. Eur J Pediatr. 2007; 166:671-8.

6. Springer A. Assessment of outcome in hypospadias surgery- a review. Front Pediatr. 2014; 2 : 2.

7. Bello A, Hussaini MY, Kura MM, Muhammed A, Tijjani LA. Hypospadias: 10 year review of outcome of treatment in pediatric urological practice. SubSaharan Afr J Med 2015; 2:28-32.

8. Hoag CC, Gotto GT, Morrison KB, Coleman GU, Macneily $A E$. Long-term functional outcome and satisfaction of patients with hypospadias repaired in childhood. Can Urol Assoc J. 2008; 2:23-31. 
9. Lu W, Tao Y, Wisniewski AB, Frimberger D, Kropp BP. Different outcomes of hypospadias surgery between north america, europe and china: Is patient age a factor? Nephrourol Mon. 2012; 4(4):609-12.

10. Snodgrass W, Bush N. TIP hypospadias repair: A pediatric urology indicator operation. J Pediatr Urol. 2016 Feb; 12(1):11-18.

11. Snodgrass W, Bush N. Primary hypospadias repair techniques: A review of the evidence. Urol Ann 2016; 8:403-408.
12. De Win G, Cuckow P, Hoebeke P, Wood D. Long-term outcomes of pediatric hypospadias and surgical intervention. Ped Health Med Ther 2012; 3: 69-77.

13. Jan I A, Mirza F, Yaqoot, Ali M, Arian A, Saleem N, Ahmad, Kumar D. Factors influencing the results of Surgery for Hypospadias: Experience at NICH. J Pak Med Assoc. 2004; 54(11):577-9.

\begin{tabular}{|c|l|l|l|}
\hline \multicolumn{3}{|c}{ AUTHORSHIP AND CONTRIBUTION DECLARATION } \\
\hline Sr. \# & \multicolumn{1}{|c|}{ Author-s Full Name } & \multicolumn{1}{|c|}{ Contribution to the paper } & Author=s Signature \\
\hline 1 & Muhammad Ali Sheikh & $\begin{array}{l}\text { Concept, Data Analysis, } \\
\text { Manuscript writing. }\end{array}$ \\
\hline 2 & Tariq Latif & $\begin{array}{l}\text { Proof reading. } \\
\text { Ahmil Akhter Munir }\end{array}$ & Data collection. \\
\hline
\end{tabular}

